\title{
Wittgenstein on Going On
}

\author{
Hannah Ginsborg \\ Department of Philosophy, University of California, Berkeley \\ Email: ginsborg@berkeley.edu
}

\section{Introduction}

In a famous passage from the Philosophical Investigations, Wittgenstein describes a pupil who has been learning to write out various sequences of numbers in response to orders such as " +1 " (for the natural numbers) and " +2 " (for the series $0,2,4,6,8 \ldots$ ). He has shown himself competent for numbers up to 1000 , but when we have him continue the " +2 " sequence beyond 1000 , he writes the numerals 1004, 1008, 1012. As Wittgenstein describes the case:

We say to him, “Look what you're doing!” - He doesn't understand us. We say “You should have added two; look how you began the series!" - He answers: "Yes! Isn't it right? I thought that's how I should [sollen] do it. - Or suppose he were to say, pointing to the series, "But I went on in the same way!" (PI $\$ 185)^{1}$

The passage continues:

- It would now be no use to us to say "But don't you see...?” - and repeat for him the old explanations and examples. - In such a case, we might perhaps say: this person naturally understands our order, once given our explanations, as we would understand the order "Add 2 up to 1000,4 up to 2000,6 up to 3000 , and so on." (ibid.)

This example of the aberrant pupil has generated a lot of discussion. It is clear that Wittgenstein intends to use it to say something about the phenomenon of rule-following, but it is not at all clear what that is. There has been considerable disagreement, in particular, about whether the example is intended to challenge our ordinary understanding of rule-following and meaning, or whether it is intended only to undermine certain philosophical myths about it, leaving our ordinary understanding of those phenomena untouched. In this paper, I argue that the example has been misinterpreted by some of the most influential participants in the discussion, and I propose an alternative interpretation which, I think, does better justice to Wittgenstein's aims in the rulefollowing considerations. I argue that the example highlights a distinctive phenomenon, which I will label "going on," and which consists-at a first approximation-in behaviour involving conscious conformity to previous behaviour, as in the case of continuing a simple arithmetical series. Crucially, I will argue, we cannot make sense of this phenomenon by identifying it with the repeated application of a rule or concept grasped by the person continuing the series (say the concept of adding two, or the rule add two). Rather, as I argue, the idea of being able to "go on" with a

\footnotetext{
${ }^{1}$ Translations of Wittgenstein, intended to be as literal as possible, are my own, but I have drawn on the translations in the editions cited in the References. Citations from Wittgenstein use the following abbreviations: BB for The Blue and Brown Books, LFM for Lectures on the Foundations of Mathematics, PI for Philosophical Investigations, RFM for Remarks on the Foundations of Mathematics, and $Z$ for Zettel.

( $)$ The Author(s) 2019. Published by Canadian Journal of Philosophy. This is an Open Access article, distributed under the terms of the Creative Commons Attribution licence (http://creativecommons.org/licenses/by/4.0/), which permits unrestricted re-use, distribution, and reproduction in any medium, provided the original work is properly cited.
} 


\section{Hannah Ginsborg}

series such as " $0,2,4,6,8 \ldots$ ” is more fundamental than the idea of applying a rule such as add two: it is something that explains, rather than something that needs to be explained by, our capacity to grasp and apply rules and concepts. ${ }^{2}$ It is a part of this alternative understanding that the passage highlights a distinctive kind of normativity associated with going on. The pupil who writes "1004" is going wrong, not in the sense that he is failing to accord with a rule that either he or his teachers had in mind, but in a more primitive sense: he is simply failing to accord with what he did previously, where this failure of accordance need not be made out in terms of the violation of a rule. The notion of "going on" thus incorporates an idea of primitive normative fit between an item of behaviour and the behaviour that precedes it, an idea that I will try to clarify in what follows.

\section{Two lines of interpretation}

I will begin by describing the more traditional of the two interpretations, which understands the passage as part of an argument challenging the possibility of rule-following and meaning as those phenomena are ordinarily understood. This kind of interpretation has been offered by Michael Dummett, Crispin Wright, and Saul Kripke, among others; the sketch I offer draws on elements from Wright and Kripke.

On our commonsense understanding of rule-following, on this line of interpretation, rules in some sense normatively determine behaviour, or require certain pieces of behaviour from us rather than others, in that they determine those pieces of behaviour as correct rather than incorrect. Grasping a rule, accordingly, is a matter of knowing what is required of us by the rule in these various contexts: so, for example, to grasp the add-two rule is to grasp, among other things, that it is required, once one has written "1000," to write "1002." And the same can be said of grasping the meaning of an expression, for example the expression " +2 " as it is used in Wittgenstein's example, since grasping the meaning of that expression is roughly equivalent to grasping the corresponding rule. But the example of the pupil, on this interpretation, is supposed to call into question this ordinary understanding. The example appears to show that any given stretch of a person's observable behaviour, for example, developing the series " $0,2,4,6,8 \ldots$ ". up to 1000 , is compatible with his or her correctly following any number of rules: not just the add-two rule but the nonstandard rule-call it the schmadd-two rule-that the pupil seems to have caught on to. So, it would seem, nothing about a person's observable behaviour in the past can justify our claiming that one item of behaviour in the future rather than any other can be correct or incorrect.

Now, so far, this does not appear to threaten the possibility of rule-following itself, but only our knowledge of what rules another person is following, and hence, which behaviour is required of her if she is to accord with whatever rules those are. Even if we can never be confident about what rule another person associates with the expression " +2 ," it might be supposed, we can have no doubt in our own case about the content of the rule we are following, and hence about what another personfor example, the pupil-is required to write after " 1000 " if she is to accord with that rule. However, as Wittgenstein goes on to indicate in the section following his introduction of the example, we are

\footnotetext{
${ }^{2}$ In common with most other participants in this debate, I understand the notions of rule and concept as applying at the personal rather than the subpersonal level. On a notion of concept that is common among cognitive psychologists and philosophers of a naturalistic bent, the concepts add two or tree are subpersonal mental representations that enable a subject (human or animal) to continue a series such as " $0,2,4,6,8 \ldots$ " or to produce a distinctive response to trees in contrast to other stimuli. Similarly, for Chomsky, to grasp a grammatical rule is for the mind/brain to have a certain structure that enables a person to produce and understand a certain range of sentences. But I am here assuming a more demanding conception of rules and concepts on which there is more to a subject's grasp of a rule than the presence of a neural mechanism that enables the subject to engage in a certain pattern of behaviour (even, as in the case of grammar, where the behaviour is quite complex).

${ }^{3}$ Dummett 1959; Wright 1980 (especially chapters 2, 11, and 12); Wright 2001 (especially the essays "Following a Rule," "Rule-Following, Objectivity, and the Theory of Meaning," and "Wittgenstein's Rule-Following Considerations and the Central Project of Theoretical Linguistics"); Kripke 1982.
} 
in no better a position to determine in our own case what is required by our supposed rules than we are in the case of another person. He imagines an interlocutor who answers the question "How is it decided what is the right step to take at any particular point?" by answering, "The right step is the one which accords with the order-as it was meant [gemeint]" (PI \$186) The force of the interlocutor's answer is that the pupil is going wrong because what he writes does not accord with the rule that we meant or intended him to follow when we gave the order " +2 "- that is, with the rule or concept which we take to be picked out by the expression " +2 ." Wittgenstein responds to the interlocutor by asking rhetorically:

So at the time you gave the order " +2 ", you meant that he was to [sollen] write 1002 after 1000 - and did you at that time also mean that he should write 1868 after 1866, and 100036 after 100034, and so on — an infinite number of such sentences? (PI \$186)

When, in trying to determine what should be written after "1002," we look back at our own minds to determine what we then meant or intended for that particular eventuality, we find nothing specific that identifies " 1004 " as the correct thing to write. ${ }^{4}$ So we are in no better a position to know what is called for by " +2 ," as we previously understood it, than we are to know what is called for by " +2 " as the pupil previously understood it. ${ }^{5}$ The upshot is that our ordinary conception of rule-following, as understood on this line of interpretation, is fatally flawed. We cannot make sense of the idea of grasping something that tells us what counts as correct or incorrect behaviour in an indeterminate number of future contexts. And, as a result, it appears, we can never tell of any continuation that it is right rather than wrong. ${ }^{6}$

I turn now to the second line of interpretation, according to which Wittgenstein's point is not to raise a problem for the possibility of rules and meaning, but rather to expose and undermine a false picture, which makes it seem as though there is a problem. The major proponent of this line of interpretation is John McDowell, and a related view has been put forward by Barry Stroud. ${ }^{7}$ As McDowell sees it, there is nothing wrong with the idea of our having something in mind that determines that it is correct to write "1002" after "1000," "1868" after "1866," and so on, in an indefinite number of instances. Nor is there anything wrong with the idea that, in observing someone write the sequence " $0,2,4,6,8 \ldots$ " up to 1000 , we can recognize that she is following the rule to add two, and not some bizarre alternative like the schmadd-two rule. ${ }^{8}$ Both in our own case and in that of others, we can know which rule is being followed, in a sense that implies our knowing what is required in any particular instance. The error Wittgenstein wants to expose is that of supposing that this knowledge has to be available from what McDowell describes as a sideways-on perspective, one that is available to someone outside practices like that of adding two.?

\footnotetext{
${ }^{4}$ As the continuation indicates, we might recognize, looking back, that when we earlier said " +2 ," we meant add the next number, but one after every number you write. But that just pushes the problem back: we might have said to ourselves the sentence "Add the next number but one after every number you write," but what did we then mean by that sentence? (Perhaps, at the time, by "every number" we meant "every number up to 1000.")

${ }^{5}$ The point about the symmetry between the first- and third-person cases is succintly made at PI $\$ 211$. "However you instruct him in continuing the ornamental pattern, how can he know how he is to go on by himself?-Well, how do $I$ know?" See also e.g. $R F M$ IV $\$ 8, R F M$ VI $\$ 17, L F M 28$.

${ }^{6}$ Proponents of this line of interpretation typically read Wittgenstein as supplementing this dismantling of the ordinary conception of rule-following with a revisionist account in terms of conformity to a community practice (e.g. the "skeptical solution" to the rule-following problem ascribed to Wittgenstein in Kripke 1982, ch. 3), but, for the purposes of this paper, I will disregard this aspect of the interpretation.

${ }^{7}$ See "Wittgenstein on Following a Rule" and "Meaning and Intentionality in Wittgenstein's Later Philosophy," both in McDowell 1998b. For Barry Stroud's view, see, in particular, "Mind, Meaning, and Practice” in Stroud 2000. I discuss Stroud's view in Ginsborg 2011a. William Child (2011, ch. 5) is sympathetic toward the quietist view but suggests that there are strands in Wittgenstein's thought that point toward the opposed approach.

${ }^{8}$ See $\$ 3$ of “Another Plea for Modesty" in McDowell 1998a, 116-117.

${ }^{9}$ See $\$ 3$ of “Non-Cognitivism and Rule-Following” in McDowell 1998b, 207-209.
} 


\section{Hannah Ginsborg}

A version of this error, according to McDowell, is to suppose that grasping a rule, or grasping the meaning of an expression, always requires interpretation. ${ }^{10}$ Consider the point that nothing in my own mind seems to determine any future behaviour of mine as correct or incorrect, since anything in my own mind (for example the words "add two" or "write the next but one number after every number you write") can be interpreted so as to be compatible with any future course of behaviour. McDowell's response is to point out that this excludes the possibility that those words are already endowed with meaning: more generally, that I can have in my mind not just bare meaningless sounds or marks, or inert sensations or images, but items with intentional content. For McDowell, it is precisely the point of the example of the pupil to expose this error. That example shows us that if we are limited to the materials available to a sideways-on view-that is, the view of someone who does not speak the language of the person exhibiting verbal behaviour, or who does not participate in practices such as counting by two-we cannot know either what rule someone else is following or what rule we ourselves are following. By the same token, we cannot know either what others mean or what we ourselves mean by our words. But the point is not to show that we lack that knowledge, and so to undermine the possibility of rule-following and meaning. Rather, it is to undermine the assumption that knowledge of meaning and rules has to be arrived at by inference from these limited materials; that it cannot be knowledge that we possess only in virtue of being participants in practices such as adding numbers or speaking a language.

\section{An objection to McDowell's interpretation}

The two interpretations I have distinguished are very different, but I think that they embody the same mistaken assumption. I will get to that assumption in Section 5. Before that, I will pave the way by first raising an objection to McDowell's interpretation (in this section) and then offering an alternative interpretation (in Section 4). As we have seen, McDowell reads PI $\$ 185$ as indicating that grasp of which rule one is following, and hence of what one ought to write after " 1000 " in continuing the series " $0,2,4,6 \ldots$," is available only to participants in practices such as counting by two. Relatedly, when he describes the activity of continuing the series, he describes it in a way that assumes that the person doing it has already grasped the add-two rule or the meaning of the expression " +2 ." Here is how he sets up the issue he takes to be raised by PI $\$ 185$ :

Suppose someone correctly understands the meaning of, say, "Add 2." Her understanding must be something with which, if she is aiming to put that understanding into practice and has reached "996, 998, 1000" in writing out the resulting series, only writing "1002" next will accord. It seems essential to be able to make this kind of use of notions like that of accord if we are to be entitled to think in terms of meaning and understanding at all. (McDowell 1998b, 263)

This passage indicates that McDowell sees the activity of continuing the series, in the normal case, as one in which someone puts into practice her understanding of the instruction " +2 " or her grasp of the add-two rule by applying it successively to the result of each of her previous applications of it. ${ }^{11}$ At each of those successive steps, her application accords with how she understands the expression or with how she grasps the rule. Now, as we saw, the first kind of interpretation raises a problem about how there can be this kind of accord: how it is that something in a person's mind can require,

\footnotetext{
${ }^{10}$ See "Wittgenstein on Following a Rule" and "Meaning and Intentionality in Wittgenstein's Later Philosophy," both in McDowell 1998b.

${ }^{11}$ In "Virtue and Reason," McDowell describes extending a series of numbers as "an exercise of rationality in which there is a formulable rule, of which each successive action can be regarded as an application, appropriate in the circumstances arrived at" (1998b, 58). In "Non-Cognitivism and Rule-Following," he implies that we should understand it as a succession of "applications of a single concept to different objects" (1998b, 203). These passages suggest a similar picture to that described in the text.
} 
or determine as correct, one particular number rather than another at any point. But according to McDowell's way of describing the activity, this problem does not arise, because he takes for granted that the person continuing the series has in her mind an item with intentional content, the content "add two," which intrinsically requires that, after "1000," she write "1002" rather than "1004."

This depiction of the activity, however, does not square with Wittgenstein's ascription of it to a pupil-that is, someone who is in the process of learning arithmetical rules and the meaning of instructions such as "add two," not someone who already grasps them. The importance of the subject's status as a pupil becomes clear when we note that the passage is presented, not in isolation, but in the context of a longer narrative that began earlier in the Philosophical Investigations and that includes the pupil (presumably a child) being taught, first to write the individual numerals 0 through 9 , and then to develop the series of natural numbers. ${ }^{12}$ Wittgenstein describes the process of learning to write the individual numerals as follows:

First of all, series of numbers are written down for him, and he is required to copy them....At first perhaps we guide his hand in writing out the series 0 to 9; but then the possibility of getting him to understand [die Möglichkeit der Verständigung] will depend on his going on to write it down independently. ${ }^{13}$ (PI $\left.\$ 143\right)$

As the remainder of the section indicates, there are various mistakes the pupil might make in the learning process: for example, he might copy the numerals 0 through 9 correctly, but get them in the wrong order. In the end, though, we are asked to suppose that the pupil has mastered writing the sequence 0 through 9 correctly and that the teaching process continues. Wittgenstein says at $\$ 145$ :

Now I continue to guide him through the series and draw his attention to the recurrence of the first series in the units; and then to its recurrence in the tens. (Which means only that I use particular emphases, underline figures, write them one under another in such-and-such ways, and similar things.) - And now at some point he goes on with the series by himself - or he does not. (PI \$145).

This sets the stage for $\$ 185$, where the pupil has apparently mastered the series of natural numbers-that is, the " +1 " series-and is now taught to respond to other commands such as " +2 " and " +3 " by writing every second number or every third number.

Now, in the more basic cases described in $\$ 143$ and $\$ 145$ (learning to write the individual numerals, learning to write the sequence 0 through 9 , learning to write larger numbers in the decimal system), there is no role for grasping the meaning of an expression. Expressions such as " +1 " or " +2 " are not introduced until a pupil has already (at least, as far as we know) mastered the decimal system. It is only at that point that the pupil is introduced to " +0 " for writing the same number again and again, " +1 ” for the sequence of natural numbers, " +2 " for every other number, and so on. So, if we treat the adding-two case as continuous with the more basic cases, as Wittgenstein apparently intends us to do, it is a distortion to think of a normal pupil developing the series in the terms proposed by McDowell-that is, as putting into practice her previously attained understanding of the expression " +2 ." For when she was learning to develop the series of natural numbers, in the way described at $\$ 143$ and $\$ 145$, she had not yet been introduced to the expression " +1 ," so there could be no question of her applying her understanding of what that expression meant.

\footnotetext{
${ }^{12}$ Note that the section begins with an explicit reference to $P I \$ 143$, where the narrative begins.

${ }^{13}$ In translating die Möglichkeit der Verständigung as "the possibility of getting him to understand," I follow Anscombe's translation (Wittgenstein 1953) in contrast to that of the revised fourth edition (Wittgenstein 2009), which has "the possibility of communication.” The significance of this will become evident when I cite the passage again in Section 4.
} 
McDowell might reply that, even if we do not think of such a pupil as applying her understanding of the expression " +2 ," we can still think of her as applying the rule for adding two-a rule she has already grasped-even if she has not yet been introduced to a linguistic expression corresponding to it. This would preserve the spirit, if not the letter, of his understanding of the case. But this still seems to me to be a distortion and to miss the significance of the exercise that Wittgenstein describes the pupil as engaging in. Two considerations are relevant here. First, when we consider the question of how a child comes to grasp rules such as "write the same numeral," "add one", and "add two," it is plausible to suppose that she does so by learning to engage in practical activities such as copying numerals that have been written out for her, writing out segments of the series of natural numbers, and writing out series of numbers where every other number is left out. Rather than these activities presupposing grasp of the rules, in the sense implied by the suggestion that they "put into practice" an already-achieved grasp of the rules, engaging in them seems to be an essential part of what is involved in coming to grasp those rules. And, as we will see in the next section, this appears to be Wittgenstein's own view of the matter.

Second, if we simply assimilate the activity to that of the repeated application of a rule that one has already grasped, then we fail to make anything of the fact that the examples specifically involve the continuation of a series, where each piece of behaviour is carried out in reference to previous behaviour - that is, to the previous steps taken either by oneself or by one's teachers. If the activity were meant to illustrate the repeated application of a rule or concept, then Wittgenstein could equally well have used examples such as repeatedly applying the concept red or even number to arbitrary red things or even numbers. ${ }^{14}$ Or he could have used the same example of writing the numbers " $0,2,4,6,8$ " and so on, but described the series not as the "add-two" series but as the "times-two" series-that is, the series that results from applying the rule "times two" or the formula " $x=2 n$ " to each of the natural numbers in succession. The activity of successively applying that rule or formula to each of a series of numbers-for example, the series of natural numbers-is a clearer and more straightforward example of putting into practice one's grasp of a rule than the activity of adding-two as described by Wittgenstein, since if we think of adding-two as the repeated application of a rule, we have to think of the rule (as expressed, say, in the formula " $x=n+2$ ") as applied successively to the result of previous applications of the formula, which introduces a complicating element of recursion. The fact, then, that Wittgenstein chooses to focus on an example of continuing a series, rather than on a more generic example of repeatedly applying a rule or concept, suggests that he has something other than repeated concept application in mind.

\section{Going on as a distinctive phenomenon}

In the previous section, I questioned McDowell's conception of the activity of continuing a series in terms of the repeated application of one's understanding of an expression or of a rule one has grasped. The example of continuing a series in $\$ 185$ is intended to illustrate something else, and I will now try to say what that is. As a first step, I want to note that the series-continuation cases we have been looking at are part of a still broader class of cases that Wittgenstein often describes simply as cases of "going on." ${ }^{15}$ Later in PI, Wittgenstein mentions a number of such cases in the context of

\footnotetext{
${ }^{14}$ As we will see in the next section, Wittgenstein thinks that coming to understand the expression "red" is like coming to understand the expression " +2 " in that it requires learning to "go on" from examples of use given by one's teachers (or, more broadly, by members of the linguistic community one is growing up in). The suggestion I am making here is not that the distinctive phenomenon of going on is restricted to cases such as the development of a series or the pattern-continuation cases discussed in the next section, but that such cases are especially helpful in bringing its distinctive character into focus. Here, my diagnosis of the significance of the series-continuation cases differs from that given by McDowell in $\$ 2$ of "Meaning and Intentionality in Wittgenstein's Later Philosophy" (1998b, 264).

15“Go on" in the standard English translations of Wittgenstein's works translates, variously, the German weitergehen, fortsetzen, fortfahren, and sometimes, fortführen.
} 
showing how we might introduce someone to concepts relevant to the notion of rule-following, for example the concept of regularity:

How do I explain the meaning of "regular," "uniform," "same" to anyone? - To someone who, say, speaks only French, I will explain these words by means of the corresponding French words. But for someone who has not yet got these concepts, I will teach him to use the words by means of examples and by means of exercises....

So in this teaching I will show him the same colours, the same lengths, the same shapes; I will have him find them and produce them, and so on. I will teach him, say, to continue ornamental series [Reihenornamente] "uniformly" when told to do so [auf einen Befehl hin]. And in addition to continue progressions. That is, for example, when given: . ..... to go on: ................ (PI \$208)

Similar examples appear in the Remarks on the Foundations of Mathematics, including the following:

I can train someone in a uniform activity. E.g., in drawing a line like this with a pencil on paper:

Now I ask myself, what is it that I want him to do [was wünsche ich. daß er tun soll], then? The answer is: He is always to go on [er soll immer so weitergehen] as I have shown him. (RFM VI \$17)

The discussion of rule-following in section VI of RFM is introduced with the example of an even simpler activity:

How does one describe the process of learning a rule?-If A claps his hands, B is always supposed to [sollen] do it too. (RFM VI \$17)

This is the kind of activity that we might teach a baby, who can learn to engage with an adult in a clapping routine well before we can plausibly ascribe to her concepts such as "clapping one's hands," let alone a rule such as "clap your hands after the other person does." Another set of examples relevant for our purposes is at $R F M$ I $\$ 3$ :

How do I know that in following the series + 2 I must [müssen] write "20004, 20006" and not "20004, 20008"?-(The question "How do I know that this colour is 'red'?" is similar.)

"But you surely know for example that you must always write the same sequence of numbers in the units place: $2,4,6,8,0,2,4$ and so on." -Quite right! the problem must also already appear in this sequence, and even in this one: 2, 2, 2, 2, etc.-For how do I know that I should [sollen] write " 2 " after the five hundredth " 2 "?, that is, that in this position " 2 " is the same figure? (RFM I, §3).

We can read this passage as alluding both to the adding-two activity described at $\$ 185$, and, in the case of the repeated writing of "2," to the child's activity of copying a numeral described at $\$ 143$. And it also suggests that whatever moral we are to draw from the cases of arithmetical series applies also to non-arithmetical cases of going on, such as going on with our use of the word "red" after having been shown examples of various red things.

The fact that these activities are of a kind typically carried out by small children, and, relatedly, that Wittgenstein supposes them to be carried out by subjects who have not yet got concepts such as "regular," "uniform" or "same," indicates that they should not be understood as requiring the application of rules that are already grasped. Rather, becoming competent in these activities seems 
to be a prior condition of coming to grasp rules and concepts. This is suggested, in addition, by Wittgenstein's saying about the pupil learning the series of natural numbers:

At first perhaps we guide his hand in writing out the series 0 to 9; but then the possibility of getting him to understand [die Möglichkeit der Verständigung] will depend on his going on to write it down independently. $(P I \$ 143)^{16}$

In Zettel, he also makes a point of emphasizing that we can teach these activities without ever specifying rules, relying instead simply on examples:

You must remember that there may be such a language-game as "continuing a series of digits" in which no rule, no expression of a rule is ever given, but learning happens only through examples. ( $Z \$ 295)$.

In another passage from Zettel, he says:

I teach him to continue a series (basic series), without using any expression of the "law of the series"; rather, I am forming a substratum for the meaning of algebraic rules or what is like them. $(Z \$ 300)$

The remark about a substratum suggests that learning these activities can be thought of as a precursor to grasping rules and concepts: we come to grasp the rule for adding two by becoming competent in continuing the series " $0,2,4,6,8 \ldots$. " It follows that, as I already suggested in Section 3 , competence in continuing the series cannot be something that presupposes antecedent grasp of that rule.

But, at the same time, Wittgenstein seems committed to the idea that the series- or patterncontinuing activities are to be understood in normative terms, as involving a requirement to do one thing rather than another at each point in the activity. To begin with, it is clear that the person teaching a child such an activity takes there to be something that she should do at each point in the activity. As we saw in the passage quoted above from RFM VI $\$ 17$, when I train someone in the activity of drawing a pattern of dashes alternating with pairs of dots, I think that he "should always go on" [soll immer so weitergehen] as I have shown him. This implies that I take the examples I have given to determine a correct piece of behaviour at each point: after a dash, the correct thing to draw is two dots, and if the pupil follows a dash with another dash rather than two dots, I will think that he has failed to do what he should, what is appropriate at that point. There is a similar normative implication in the description of the child's clapping activity: "If A claps his hands, B is always supposed to [sollen] do it too" (RFM VI \$17). Moreover, Wittgenstein suggests that this rightness is something that can be recognized, not just from an outside perspective-say, by the teacher-but by the person who is learning the activity. In the example from $P I \$ 185$, when we try to correct the pupil who continues the series after "1000" by writing "1004," he answers, "Yes, isn't it right? I thought that was how I should do it." Presumably, a pupil who went on the normal way by writing " 1002 " would also claim that he was doing what he ought, or what was correct or appropriate, in that context. There is a similar implication in the parallel passage, quoted earlier, from RFM I $\$ 3$ : “How do I know that in following [verfolgen] the series +2 I must [müssen] write '20004, 20006' and not '20004, 20008'?” The question how I know that I must write "20006" after "20004" implies that I at least believe

\footnotetext{
${ }^{16}$ See note 13. The point I am making is not undermined if we translate Möglichkeit der Verständigung as "possibility of communication," assuming that our ability to communicate with the pupil depends on his understanding the decimal system, but Anscombe's translation makes it clearer.
} 
that I must. And after describing several cases of going on at RFM VI, Wittgenstein has his interlocutor say:

I know at every step what I have to do [zu tun haben]. I see it quite clearly before me. It may be boring, but there is no doubt what I have to do. (RFM VI §47)

The suggestion is again that it is part of engaging in these activities of going on-developing simple arithmetical series, continuing abstract patterns, even playing a simple game of taking it in turns to clap hands - that we take what we do at each step to be something that is required of us; that is to say, the correct thing to do. ${ }^{17}$

At first sight there might appear to be a conflict between the two implications I drew out of the passages we just looked at. How are we to reconcile the idea that a pupil who writes "1002" after "1000" recognizes what she does as correct with the idea that she does not have a rule in mind that tells her that "1002" is the thing to write? I think the answer is to see Wittgenstein as committed to an idea of correctness that is not equivalent to the idea of conformity to a rule. Correctness, on this idea, can consist in conformity to previous behaviour, but without that conformity being mediated by a rule. In the case of the pupil at $P I \$ 185$, the behaviour of writing " 1002 " fits or accords with his behaviour in writing the numerals he wrote previously in a way that writing "1004" does not. Writing " 1002 " is going on correctly from that previous behaviour; writing " 1004 " is not. But this is not in virtue of the fact that the previous behaviour exemplifies the rule add two rather than what I earlier called the schmadd-two rule. We do not need to conceive of the previous behaviour as exemplifying a rule in order to conceive of " 1002 " as according with it. Rather, we can conceive of writing "1002" as according with the previous behaviour simpliciter. Someone presented with the pattern of numerals " $0,2,4,8 \ldots 996,998,100$ " in the kind of learning context Wittgenstein describes can recognize the appropriateness of "1002" in a sense that does not have to be explicated in terms of its fitting the rule or principle of the series. This means that her confidence in the correctness of " 1002 " cannot be undermined by a skeptical argument à la Kripke to the effect that she might have been following the schmadd-two rather than the add-two rule. For it is not based on any assumption about what rule she was following. Regardless of whether she was following the add-two rule or the schmadd-two rule, she can say that it is " 1002 " that is called for now, given her previous behaviour.

In previous work, I have characterized this notion of appropriateness as "primitive normativity": primitive both in the sense of not being analyzable in terms of the relation of behaviour to a rule, and in the related sense that we can ascribe it to subjects who are not yet masters of a language. ${ }^{18}$ This notion, as I understand it, is not restricted to cases such as continuing a series. For example, I take it to be implicit in the kind of case to which Wittgenstein alludes at the end of PI \$185:

This case [of the aberrant pupil] would be like one in which a person naturally reacted to a pointing gesture with the hand by looking in the direction from fingertip to wrist, instead of looking in the direction towards the fingertip.

It is part of our natural reaction to a pointing gesture that we not only look in the direction from wrist to fingertip (as opposed to the direction from fingertip to wrist), but, in so doing, take ourselves to be

\footnotetext{
${ }^{17}$ Could it be that this recognition of normativity is available only to subjects sophisticated enough to be able to develop arithmetical series, so that it is not present in the simpler pattern-continuation cases? Against this, PI \$211 (quoted in note 5) implies that a child continuing an ornamental pattern knows just as well as I do how to go on. On the assumption that knowing how to go on involves not merely having a disposition or capacity to go on correctly, but also being able to recognize each step as correct, then this indicates that the recognition of normativity is available to less sophisticated subjects as well. Even the baby learning the clapping routine can be understood not merely to be responding to the adult's clapping his hands by clapping her own, but to be, in some sense, recognizing her own behaviour as fitting, or as the thing to do.

${ }^{18}$ See Ginsborg 2011b.
} 
responding appropriately to the gesture. We see the gesture as "calling for" our looking in that direction, rather than the gesture's merely eliciting that way of looking, as if by reflex. The normativity here, as in the series- and pattern-continuation cases, is primitive: our behaviour of looking toward the fingertip as opposed to the wrist conforms to the gesture as such, not to a general rule that we take the gesture to exemplify. But the normativity in continuing a series or a pattern is an especially important case of primitive normativity because of its role in securing the possibility of a conventional languagethat is, one involving arbitrary signs such as “ +2 " or "red." Such signs can come to be endowed with meaning, and their meaning conveyed from one person to another, only to the extent that they come to figure in pattern-continuation activities in which particular uses of the sign are recognized as correct (or not) in light of previous uses. The meaningfulness of " +2 " depends on children's being able to learn how to go on, both with activities such as copying the symbols " + " and " 2 " (in other words, continuing patterns such as " $++++\ldots$ " and "2 $2222 \ldots$ (.) and with series such as that under discussion in PI $\$ 185$. And, in each case, that learning depends on their being able to recognize individual steps as correct in the primitive sense. Arithmetical expressions such as " +2 " are a particularly good case for making this point because there the idea of continuing a pattern is especially clear. We can see a continuity between simple dot-dash patterns and the patterns formed by sequences of numerals in the decimal system, and this helps us to see the way in which each step in the arithmetical series expressed by " +2 " can seem appropriate in the light of the previous steps. But once we recognize this continuity, we can see the same kind of pattern-continuation in the case of other linguistic expressions that are taught by example. I take this to be the point of the parallel Wittgenstein draws in RFM I $\$ 3$ between the question "How do I know that in following the +2 series I must write '20004, 20006?" and the question "How do I know this colour is 'red'?" The similarity lies in the fact that both the mastery of the expression " +2 " and the mastery of the expression "red" rely on our knowing how to continue a pattern, which is, in turn, a matter of knowing, at each step, what to say or do in light of what was said and done previously. In the " +2 " case, the pattern is confined to numerals, but in the case of the expression "red," it involves objects and events in the world. Roughly, the child learning to use the word "red" learns to continue a sequence-albeit one spread out over a considerable time and with many interruptions-of utterances of "red" following or preceding the pointing to or fetching of red objects. In coming to use the word correctly for novel objects, the child is coming to recognize new uses of the word as appropriate in each new situation, where the situation includes both the novel red object and the previous sequence of behaviour with red objects and utterances of "red." Learning to go on with the word "red," in parallel to learning to go on with behaviour more easily recognizable as continuing patterns, does not depend on having grasped a rule for the use of "red" or the concept red, but is, rather, required as a condition of acquiring the corresponding rule or concept.

\section{A mistaken assumption}

I noted earlier in this paper that the two kinds of interpretation I distinguished differ with respect to whether they read PI $\$ 185$ as challenging or as defending our ordinary understanding of rulefollowing. However, they agree in assuming that, for Wittgenstein, if there is such a thing as recognizing the correct next step in an activity like the one described in the passage, it could only be because there is such a thing as grasping a rule and recognizing what it requires. This is because they assume that the kind of normative requirement that is central to our ordinary understanding of rule-following - that " 1002 " rather than " 1004 " is required of us after "1000," rather than being either a leap in the dark or something whose correctness is up to us to determine-can be understood only as a matter of accordance with a grasped rule or an item of intentional content. This assumption is implicit in McDowell's characterization of the series-continuation activity at PI $\$ 185$ as a matter of a person's successively putting into practice her grasp of the rule add two. Recognizing the correctness of "1002" is a matter of recognizing its accordance with that rule-a rule that the person is assumed to have grasped. There is no room for the possibility that "1002" could be recognized as correct independently of the recognition that it accords with some grasped rule. 
The assumption is also implicit in the first and more traditional line of interpretation, on which the difficulty Wittgenstein identifies in the idea of rule-following is a consequence of the difficulty in making out the idea that we are in a position to recognize what rule we were following or what accords with it. We can see this in Kripke's formulation of the difficulty in terms of the question of what I meant by the sign "+" in my previous uses of it. Kripke has us suppose that, having not previously used the "+" sign with arguments 57 or greater, we are asked "What is $68+57$ ?" Our confidence that we should say " 125 " is analogous to our confidence that, in developing the sequence labelled " +2 ," we should write "1002" after "1000": it is confidence that we are going on appropriately in our use of the " + " sign. According to Kripke, this confidence rests on our confidence that we previously meant addition by "+":

I am confident that I should answer " 125 " because I am confident that this answer also accords with what I meant....It ought to be agreed that if I meant plus, then unless I wish to change my usage, I am justified in answering (indeed compelled to answer) " 125 ," not " 5 ." (Kripke 1982, 11)

This makes our confidence in the correctness of " 125 " rather than " 5 " vulnerable to a skeptical challenge regarding what we previously meant by "+": if we meant not addition, but quaddition (defined so that $x$ quus $y$ is the sum of $x$ and $y$ where $x$ and $y$ are less than 57, and otherwise 5), then we ought to say " 125 ." The difficulty is thus generated by the assumption that what we ought to say in response to the query " $68+57$ ?" - or more generally, how we ought to go on with "+" for numbers 57 and above-depends on what we meant by "+" or what rule we had in mind for its use.

Wright's setting up of the difficulty embodies a similar assumption:

I undergo some process of explanation-somebody writes down for me a substantial initial segment of some arithmetical series, say-and as a result, let us suppose, I come to have the right rule "'in mind." How, when it comes to the crunch - at the nth place-does having the rule "in mind" help? (Wright 2001, 184)

Unlike Kripke, Wright does not think that Wittgenstein challenges my knowledge of what rule I used to follow. Rather, the difficulty concerns how, assuming I have some rule in mind, I can recognize what that rule requires of me at any given point. But the assumption, again, is that for Wittgenstein, if there is such a thing as recognizing what I ought to write at the $n$th place, it could only consist in recognizing what is required by some rule I have grasped. Like Kripke, Wright sees the normativity exemplified by the correctness of writing "1002" after " 1000 " as equivalent to its conformity to a rule the subject has in mind, so that, if we cannot make sense of writing "1002" as conforming to a rule in the subject's mind, then we cannot make sense of the normativity either.

If my interpretation of $P I \$ 185$ is on the right lines, however, this assumption is mistaken. According to Wittgenstein, as I read him, we can know how to go on- where this involves our recognizing the appropriate next step at each point in the sequence-without having to grasp some item of intentional content with which we can recognize ourselves as according. Relatedly, I am not required to cite a rule to justify my confidence that one way of going on, say, writing "1002," is appropriate, whereas writing " 1004 " is not. If challenged on why "1002" and not "1004" is the appropriate next step, I can simply point out that writing "1002" fits my previous behaviour and that writing "1004" does not. This last point is made clear in a number of passages in which Wittgenstein appears to reject the idea that we need to justify our confidence about the correct way to go on in any particular instance. Recall one of the passages I cited earlier as indicating that going on involves the recognition of normativity, in which the interlocutor says:

But I know at every step what I have to do [zu tun haben]. I see it quite clearly before me.

It may be boring, but there is no doubt what I have to do. (RFM VI \$47) 
Wittgenstein goes on to ask "Whence this certainty [Sicherheit]?" and replies with a series of rhetorical questions:

But why do I ask this? Isn't it enough that this certainty exists? What is the point of seeking a source for it? (RFM VI \$47).

We see a similar implication in the continuation of a passage from Zettel that I quoted earlier as indicating that learning to go on does not presuppose grasp of rules. Wittgenstein says, in his own voice:

You must bear in mind that there may be such a language-game as "continuing a series of digits" in which no rule, no expression of a rule is ever given, but learning happens only through examples. $(Z \$ 295)$

The passage continues:

So that the idea that every step should be justified by a something - a sort of pattern [Vorbild] — in our mind, would be completely alien to these people. $(Z \$ 295)$

Although the passage is not directly about us, but rather about another group of people who apparently have no practice of justifying their ways of going on in terms of rules or intentional contents, the implication is that justification in terms of appeal to grasped contents in our minds is not always necessary for the possibility of knowing how to go on, and that we can engage in activities like that in PI $\$ 185$ without them.

A third passage which speaks to this point, also from Zettel, is Wittgenstein's response to an interlocutor who suggests that someone who recognizes the correct next step but who cannot articulate a rule must be grasping the rule in some other sense that does not require the capacity to express it. The interlocutor says "He grasps the rule intuitively." Wittgenstein replies, "But why the rule? Why not how he now ought to go on [wie er jetzt fortsetzen soll]?” ( $Z \$ 303)$. Wittgenstein's thought is that we have done sufficient justice to the phenomenon of knowing how to go on once we acknowledge that the person going on is confident, at each step, of how she ought to go on. There is no need to suppose an additional element-grasp of a rule or of the meaning of an expression-by virtue of which her confidence in how she ought to go on is justified. Although, unlike the people mentioned in $Z \$ 295$, we do have a practice of invoking rules to explain and justify ways of going on under specific circumstances, this does not mean that every claim to be going on correctly depends on the possibility of citing a rule with which it accords. And in the kinds of cases of going on that we have been looking at, in which children come to grasp rules through the practical mastery of activities such as continuing a dot-dash pattern or a sequence of numerals rather than through verbal explanation, such claims cannot stand in need of justification by rules. In order for a child to become competent in the use of " +2 ," so that-if the circumstances call for it-she can invoke the add-two rule as part of a justification for writing one number rather than another, she must first be able to recognize the correctness of (say) writing " 1002 " after " 1000 " in a sense that does not depend on the possibility of justification in terms of the add-two rule. ${ }^{19}$

\footnotetext{
${ }^{19}$ Readers may be reminded here of Wittgenstein's remark that “to use an expression without justification does not mean to use it wrongfully $[z u$ Unrecht]" (PI $\$ 289 ; R F M$ VII $\$ 40)$. The view I am ascribing to Wittgenstein is certainly consistent with that remark, but it is more specific. The point is not just that there is nothing illegitimate about using an expression without a justification, but that, if we could not do so, then there could be no such thing as grasping rules for the use of expressions and, therefore, no practice of justification in terms of those rules.
} 


\section{An objection: Doing the same}

Here it might be objected that, even if a child continuing the " +2 " series does not recognize herself as according with the rule add two, she might still recognize herself as according with a more general rule along the lines of do the same as you did before or do the same as your teachers did. On this objection, what I have been calling a distinctive phenomenon of "going on," involving a normativity that is "primitive" in the sense that it is not constituted by conformity to a rule, is just a special case of rule-following as typically conceived, where the rule that is grasped and applied is the rule do the same or some variant of it. Support for this objection might be found in Wittgenstein's apparent equation, in a number of passages, of the idea of going on correctly and the idea of going on the same way. For example, at PI $\$ 185$, he supposes that the child who goes on with "1004" might say not just "Isn't it right? I thought that's how I should do it" but also "But I went on in the same way!" And at RFM I $\$ 3$, he equates the question "how do I know that I am to write ' 2 ' after the five hundredth ' 2 '?" with the question "how do I know that 'the same figure' in that place is ' 2 '?" The suggestion in both cases is that the activity is being pursued in response to an instruction involving the word "same" and that the thought of the behaviour's being correct is the thought of its successfully according with that instruction.

However, there are both textual and theoretical reasons to suppose that this suggestion gets things the wrong way round: that the thought of one's behaviour as correct does not depend on, but rather is needed to make sense of, the thought that one is doing the same as before. To begin with, as Wittgenstein points out, it is not at all straightforward to suppose that writing " 1002 " after " $0,2,4$, $6,8 \ldots 1000$ " is in fact doing the same as one was before. At PI $\$ 226$ and at RFM VII $₫ 50$, he imagines someone continuing the sequence " $1,3,5,7 \ldots$ " in expanding the series $2 x$ - 1 , and asking himself "But am I always doing the same thing, or something different every time?" 20 And at RFM VII \$51, he appears to draw the moral that the idea of doing the same cannot be invoked to explain rulefollowing: "[Cannot] the one who is following a rule nevertheless also say that in a certain sense he does something different every time? Thus whether he does the same thing or keeps on doing something different does not determine whether he is following a rule." The person who continues the sequence " $0,2,4,6,8 \ldots$ " takes herself at each step to be doing what is correct or appropriate in that context, even though she may be in doubt about whether it counts as doing the same. This suggests that the thought of oneself as "going on" correctly-that is, doing what is appropriate in the context created by one's previous behaviour-does not depend on the thought of oneself as doing the same as one did previously.

Now, of course we do ordinarily think of writing " 1002 " in the relevant context as doing the same as before, and writing "1004" as doing something different. ${ }^{21}$ But the mastery of the concepts "same" and "different" which makes this possible depends on our having learned the use of the corresponding expressions. ${ }^{22}$ And learning the use of "same," as with learning the use of " +2 " or "red," means learning how to go on from examples we have been given. As we saw from PI $\$ 208$, quoted in Section 4, we teach a child the concept same or the use of the word "same" by getting her to engage in exercises such as bringing things with the same colour or same shape, or continuing repetitive or progressive patterns (for example, ....................). A child becomes competent in the use of "same" only insofar as she can both carry out these kinds of exercises individually, and go on

\footnotetext{
${ }^{20}$ Compare the example in $L F M$ of someone who continues the series "1, $4,9,16 \ldots$ " up to the square of 99 , but then writes " 20,000 " at the hundredth place, claiming that he is doing the same with 1000 as he did with 99 . "Now what is doing the same with 100 ? - We might put the point I want to make here by saying, '99 is different from 100 in any case; so how can we tell whether something we do to 99 is the same as something we do to 100?"' (LFM 26).

${ }^{21}$ For a dissenting view, at least as regards Wittgenstein's position, see Anscombe 1985, 345.

${ }^{22}$ Compare LFM 58: we are typically not at a loss when told to do the same because "we have learnt the technique of using the word 'same."'
} 
from the use of "same" in connection with them to further uses of "same" in new contexts-for example, as applied to writing " 1002 " after being given " $0,2,4,6,8 \ldots 1000$." But this requires that she be capable of recognizing the correctness or appropriateness both of the individual steps in the training exercises and of each new use of the expression "same." She must be able to recognize that, if "same" has been used in connection with bringing a new red thing to match a sample of red, and with her behaviour in continuing . .... with .............. then it is also correct to use "same" in connection with writing " 1002 " after " $0,2,4,6,8 \ldots 1000$." And this recognition of correctness cannot be spelled out as the recognition that one is according with the rule to do the same as before, since it is a precondition for grasping the concept same. ${ }^{23}$

The argument just sketched does not exclude the possibility that, once someone has grasped the concept same, she can take "1002" to be the correct thing to write on the grounds that writing "1002" is doing the same as before and that what is required of her in this context is to do the same. But it does show that, at least in some cases-those of learning how to go on with expressions such as "same," "uniform," and "similar," and thus of coming to grasp the corresponding concepts-the thought of one's behaviour as correct or appropriate cannot depend on the thought that it accords with the rule do the same. Once we have recognized the need to invoke primitive normativity in these cases, then there is no reason not to do so also in connection with typical cases where a child is learning to continue a pattern or to go on with the use of a word. In fact, construing the normativity as primitive is preferable, since it allows us to avoid ascribing to the child attitudes that are implausibly sophisticated. Wittgenstein, in the Brown Book, refers to

a queer misunderstanding we are most liable to fall into, which consists in regarding the 'outward means' the teacher uses to induce the child to go on as what we might call an indirect means of making himself understood to the child. (BB 50)

He goes on:

We regard the case as though the child already possessed a language in which it thought and that the teacher's job is to induce it to guess his meaning in the realm of meanings before the child's mind, as though the child could in his own private language ask himself such a question as, "Does he want me to continue, or repeat what he said, or something else?" (BB 50).

The idea of primitive normativity allows us to make sense of the idea that the child can know how to go on, where that includes recognizing the next step as correct, without having to suppose that she formulates any conception of what the adults expect of her: whether that is something specific, such as adding two, or something more general, such as doing the same as before.

\footnotetext{
${ }^{23}$ If the same line of reasoning were to apply to the recognition of correctness itself, then the view that going on involves the recognition of primitive normativity would face a regress. (Adrian Haddock raises a worry for primitive normativity along these lines [2012, 158-159].) But the cases of "same" and "correct" are not parallel. In order to recognize writing "1002" as correct-that is, to recognize that we should write "1002" - we do not need to have learned how to go on with the expression "correct." This is connected with the fact that words such as "correct" and "incorrect" play a different role in language learning and concept acquisition from nonnormative expressions such as "same," "add two" and "red." Instead of themselves being associated with characteristic ways of going on, they are used to teach children how to go on. "The words 'right' and 'wrong' are used when giving instruction in proceeding according to a rule. The word 'right' makes the pupil go on, the word 'wrong' holds him back" (RFM VII \$39). How does the child come to understand them, if not by learning how to go on with them, as with "red" or "same"? An answer is suggested at RFM VI \$17: "I say to him “That's right, and this expression is the bearer of a tone of voice, a gesture. I leave him to it. Or I say 'No!' and hold him back." Expressions such as "correct" and "incorrect" are learned through their association with natural signs indicating what a child should or should not do-signs whose meaning does not have to be learned, any more than we have to learn to respond to a pointing hand by looking in one direction rather than another (cf. PI $\$ 185)$.
} 


\section{Conclusion}

If this understanding of going on is correct, what are the implications for Wittgenstein's attitude towards rule-following? Does he mean to undermine our ordinary conception of rule-following, as Wright and Kripke think, or does he mean to defend it, as McDowell thinks? I have argued that he means to defend at least one element of that ordinary conception-namely, the idea that in cases like that of PI $\$ 185$, there can be a correct next step and that we can know what it is. But I have suggested that he rejects what both lines of interpretation regard as a further element of the ordinary conception: the idea that the recognition of normativity in these cases of going on depends on grasp of an item of intentional content such that we can recognize the step in question as according with that content.

This is not to say, however, that Wittgenstein rejects the ideas of intentional content or grasp of general rules. ${ }^{24}$ Although I do not have space to defend the point adequately here, he thinks it is perfectly acceptable to think of an adult language user not only as knowing how she ought to go on, but also as grasping corresponding rules or intentional contents to which she can, at least in some contexts, appeal as a way of justifying how she goes on. What he wants to reject is a mistaken picture of the relation between the idea of the correct next step-the correct thing to do in the light of previous behaviour-and our grasp of the rule that we describe as justifying that step or determining it as correct. On that mistaken picture, which I think is shared by both kinds of interpretations I have discussed, the idea of the correct next step-or more generally, the correct thing to do in the context-depends on the idea of a rule or intentional content that has been grasped by the person carrying out the activity. So it does not make sense to think that someone could ever recognize writing "1002" as the correct thing to do without grasping a general rule such as add two or keep doing the same thing. By contrast, on the view that I take Wittgenstein to endorse, the relation is the reverse. The more fundamental notion is that of the correct thing to do in a context, or the correct next step, and we can use that notion to make sense of the idea of grasping a general rule. There is at least a suggestion of that at $P I \$ 187$, where Wittgenstein continues to engage with the interlocutor of $\$ 186$ who claimed that the right step is the one that accords with the order " +2 " "as it was meant." At $\$ 186$, as we saw, Wittgenstein mocks this suggestion by asking if the interlocutor meant not only that the pupil should write "1002" after "1000," but that he should write "1868" after "1866," "10036" after "10034," and so on for an infinite number of cases. But in $\$ 187$, he allows that there is a sense in which the interlocutor knew in advance that the pupil should write each of these things. The interlocutor says, "But I already knew, at the time when I gave the order, that he should write '1002' after '1000.” Wittgenstein replies:

Certainly; and you may even say you meant it then...Your "I already knew at the time ..." amounts to something like: "If I had then been asked what number he should write after 1000, I would have replied 1002." And that I don't doubt. This is an assumption of much the same sort as "If he had fallen into the water then, I would have jumped in after him" (PI \$187)

The suggestion is that we can mean all these cases in advance, not by having something in mind that determines each of them as correct, but by knowing how to go on from the cases with which we are already acquainted. And this is a matter of being able to recognize for any future instance, at the moment in which we are presented with that instance, what is the correct thing to write in the light of what has gone before. There is nothing wrong with saying that someone who has acquired that ability in connection with a particular expression (say, "+2") grasps a rule for the use of that expression that determines its correct application in an infinite number of cases. Someone who is competent in the use of an expression, and who can be relied upon to recognize in any given case

\footnotetext{
${ }^{24}$ Thanks to Crispin Wright for prompting the clarification in this paragraph.
} 
whether a particular use does or does not conform to previous uses, counts as grasping the corresponding rule or concept, and can even be said to have it in mind. The mistake is not to think that there is such a thing as grasping a rule, but rather to suppose that we need to appeal to the idea of grasping a rule in order to make sense of the more fundamental notion of recognizing, in individual instances, how to go on.

I return, finally, to the question at issue between the two kinds of interpretations I distinguished at the outset. Does Wittgenstein mean to challenge our ordinary understanding of rulefollowing, or does he mean only to undermine a misleading philosophical picture of it? Like McDowell and other defenders of the second line of interpretation, I opt for the latter alternative, but I disagree with McDowell regarding what the misleading picture is. Because I think that Wittgenstein wants us to consider the question of how grasp of meaning and rules is possible for subjects who are not yet masters of language or of other rule-governed practices, I do not think that he rejects the aspiration to what McDowell calls a "sideways-on" view. It seems to me that, for Wittgenstein, this aspiration reflects not a philosophical myth, but rather a question that naturally arises when we interact, in ordinary life, with children learning language. The misleading picture is, instead, one that takes our rational adult practices of justification in terms of meanings and rules to define the phenomenon of rule-following in a broad sense, as opposed to just being an aspect of it. That picture obscures the role played by our more basic capacities to go on: capacities whose exercise includes the recognition of a normativity that does not depend on justification in terms of rules. Rejecting that misleading picture and accepting the primitive normativity that figures in cases of going on helps us to a more satisfactory understanding of how Wittgenstein means to defend our ordinary conception of rule-following.

Acknowledgments. Versions of this paper were presented at the June 2018 meeting of the Canadian Philosophical Association in Toronto, at the University of Otago, and at the Oxford Philosophical Society. I am grateful to audiences on those occasions for comments and questions. Further thanks to John Campbell, Bill Child, and Alexander Miller for helpful comments on earlier versions of the material in this paper.

Hannah Ginsborg is Willis S. and Marion Slusser Professor of Philosophy at the University of California, Berkeley. She is the author of The Normativity of Nature: Essays on Kant's Critique of Judgement (2015), and of articles on a range of topics including rule-following, reasons for belief, perceptual content, the normativity of meaning, and aesthetic experience.

\section{References}

Anscombe, G. E. M. 1985. “Wittgenstein on Rules and Private Language.” Ethics 95 (2), 342-352.

Child, William. 2011. Wittgenstein. Abingdon, United Kingdom: Routledge.

Dummett, Michael. 1959. "Wittgenstein's Philosophy of Mathematics." Philosophical Review 68 (3), 324-348.

Ginsborg, Hannah. 2011a. "Inside and Outside Language: Stroud's Nonreductionism about Meaning." In The Possibility of Philosophical Understanding, edited by Jason Bridges, Niko Kolodny, and Wai-Hung Wong, pp. 147-181. Oxford: Oxford University Press.

Ginsborg, Hannah. 2011b. “Primitive Normativity and Skepticism about Rules.” Journal of Philosophy 108 (5), $227-254$.

Haddock, Adrian. 2012. "Meaning, Justification, and 'Primitive Normativity." Proceedings of the Aristotelian Society, Supplementary Volume, 86 (1), 147-174.

Kripke, Saul. 1982. Wittgenstein on Rules and Private Language. Cambridge, MA: Harvard University Press.

McDowell, John. 1998a. Meaning, Knowledge, and Reality. Cambridge, MA.: Harvard University Press.

McDowell, John. 1998b. Mind, Value, and Reality. Cambridge, MA: Harvard University Press.

Stroud, Barry. 2000. Meaning, Understanding and Practice. Oxford: Oxford University Press.

Wittgenstein, Ludwig. 1953. Philosophical Investigations, Translated by G.E.M. Anscombe. London: Macmillan.

Wittgenstein, Ludwig. 1958. The Blue and Brown Books. Oxford: Basil Blackwell.

Wittgenstein, Ludwig. 1967. Zettel. Edited by G.H. von Wright and G.E.M Anscombe. Translated by G.E.M. Anscombe. Oxford: Basil Blackwell.

Wittgenstein, Ludwig. 1978. Remarks on the Foundations of Mathematics. Edited by G.H. von Wright, Rush Rhees, and G.E.M Anscombe. Translated by G.E.M. Anscombe. Rev. ed. Oxford: Blackwell. 
Wittgenstein, Ludwig. 1976. Lectures on the Foundations of Mathematics, Cambridge, 1939. Edited by Cora Diamond. Hassocks, Sussex: Harvester Press.

Wittgenstein, Ludwig. 2009. Philosophical Investigations.4th ed. Edited by Peter Hacker and Joachim Schulte. Translated by G. E. M. Anscombe, Peter Hacker, and Joachim Schulte. Oxford: Wiley-Blackwell.

Wright, Crispin. 1980. Wittgenstein on the Foundations of Mathematics. London: Duckworth.

Wright, Crispin. 2001. Rails to Infinity. Cambridge, MA: Harvard University Press.

Cite this article: Ginsborg, H. 2020. Wittgenstein on Going On. Canadian Journal of Philosophy 50: 1-17, doi:10.1017/ can.2019.48 